\title{
ENERJİ NAKİL HATLARI GÜZERGÂH TESPİTİ VE PROJE ÇİZIMİNİN OTOMASYONU
}

\author{
Hasan EROĞLU ${ }^{1}$, Musa AYDIN ${ }^{2}$ \\ ${ }^{1}$ Gümüşhane Üniversitesi, Mühendislik ve Doğa Bilimleri Fakültesi, Elektrik-Elektronik Müh. Bölümü, \\ Gümüşhane \\ ${ }^{2}$ Selçuk Üniversitesi, Mühendislik Fakültesi, Elektrik-Elektronik Mühendisliği Bölümü, Konya \\ hasan.eroglu@gumushane.edu.tr, aydin@selcuk.edu.tr
}

(Geliş/Received: 10.04.2015; Kabul/Accepted: 11.09.2015)

\begin{abstract}
ÖZET
Geçmişten günümüze kadar sürekli artış gösteren enerji talebini karşılayabilmek için yeni Enerji nakil hatlarına $(\mathrm{ENH})$ ihtiyaç vardır. Yeni ENH'ler için en uygun güzergâhın tespiti ve projesinin çizimi, mühendisler için oldukça zaman alan ve karmaşık bir problemdir. Literatürde ENH'lerin en uygun güzergâhının tespiti için birçok çalışma yapılmıştır. Ancak tüm bu işlemleri bir araya getirerek güzergâh tespitini kolaylaştıracak ve belirlenen bu güzergâhta hattın profilini çizerek projelendirmesini yapabilecek bir yazılım ihtiyacı olduğu görülmektedir. $\mathrm{Bu}$ çalışmada, ENH'lerin en uygun güzergâh tespitinin yapılabilmesi için Coğrafi bilgi sistemlerini (CBS) kullanan bir ara yüz tasarlanmış, belirlenen güzergâh için ENH projesinin profilini çizebilen ve diğer tüm proje işlemlerini gerçekleştirebilen bir çizim programı yazılmıştır. Ayrıca ENH projelerinin görsel olarak üç boyutlu arazi modeli ve uydu fotoğrafi üzerinde gösterimi yapılarak kullanıcıların projeyi gerçek arazi modeli üzerinde kontrol edebilmeleri sağlanmıştır.
\end{abstract}

Anahtar Kelimeler: Enerji nakil hattı (ENH) güzergah tespiti, güzergah optimizasyonu, ENH proje çizimi, enh projelerinin üç boyutlu gösterimi

\section{AUTOMATION OF ELECTRICAL TRANSMISSION LINES' ROUTE OPTIMIZATION AND PROJECT DRAWING}

\begin{abstract}
There is a need for new Energy transmission lines (ETL) in order to meet the energy demand that has been increasing from past to present. Finding the optimum route and drawing the project is a time consuming and a complex problem for engineers. There are many studies for optimization of ETL's routing in the literature. However it is seen that there is a need for an interface that will facilitate the ETL routing by bringing together all the processes for ETL routing and preparing the project of the ETL by drawing the profile of the route. In this study, an interface using the Geographical information systems (GIS) is designed for finding the optimum route of ETL's, a project drawing program that can draw the profile and make all the other project processes is written. Also, controlling the project on the real terrain model by the users is ensured by the visualization of the ETL's projects on three-dimensional terrain model and satellite image.
\end{abstract}

Keywords: Energy transmission Line (ETL) route determination, route optimization, ETL project drawings, three-dimensional representation of the ETL project

\section{GÍRIŞ (INTRODUCTION)}

Türkiye'de ve sürekli gelişen ülkelerde nüfusun, sanayileşmenin ve hayat kalitesinin artması [1] yeni enerji kaynaklarının inşa edilmesi, artan enerji talebini mevcut ENH'lerin karşılayamaması, göç ve hızlı nüfus artışı, ENH'lerin eskimesi, verimli tarım arazilerinin azalması, kentleşmenin artışı vb. sebeplerden dolayı yeni ENH'lerin inşa edilmesi kaçınılmazdır. Türkiye'de üretilen enerji, Türkiye Elektrik İletim Anonim Şirketinin (TEİAŞ) y1llık istatistiklerine göre her yıl bir önceki yıla göre 
yaklaşık olarak \% 10,56'lık bir artış göstermektedir. Enerji nakil hatlarının uzunluğu ise her yıl yaklaşık olarak \%3'lük bir artış göstermektedir. Bu değerler, 2012 yılında yapılacak ENH uzunluğunun yaklaşık olarak Türkiye'nin en doğusuyla en batısı arasındaki mesafe kadar olacağı sonucunu vermektedir ve bu mesafe ülkenin gelişimiyle her yıl daha da artacaktır. İnşa edilmesi gereken bu ENH'lerin güzergâh tespiti için günümüze kadar uygulanan klasik yöntem, farklı disiplinlerden birçok insanın bir araya gelerek basılı haritalar yardımıyla en uygun güzergâhı bulması çalışmasıdır [2]. Fakat bu klasik yöntemde, projeyi etkileyen faktörlerin bir bütün olarak incelenememesi ya da bu faktörlerin birbirlerine göre önem derecelerinin belirlenmesinde hatalar [3] ENH güzergâhının belirlenmesindeki klasik yöntemin bazı dezavantajlarıdır. ENH ile ilgili belirlenen kriterlere ait verilerin basılı haritalar üzerinden analiz edilerek güzergâhın tespiti oldukça zordur. Günümüzde, coğrafi verilerin toplanması, analiz edilmesi ve sonuca hızlı bir şekilde ulaşılması CBS yardımıyla mümkün olabilmektedir [3-5]. Ayrica ENH güzergâhına ait ağırlık değerlerini içeren verilerin bir araya getirilmesi ve bir bütün olarak değerlendirilerek ENH güzergâhına ait Ağırlıklandırılmış Maliyet Haritasının (AMH) elde edilmesi de CBS ile mümkündür. $\mathrm{Bu}$ nedenle $\mathrm{CBS}$, güzergâh belirleme çalışmalarında ve diğer mühendislik çalışmalarında oldukça yaygın olarak kullanılmaktadır [2, 3, 6-18].

ENH güzergâh belirleme çalışmalarında, güzergâha etki eden kriter ağırlık değerlerinin düzenlenebileceği, bir veri tabanı yardımıyla ekleme, çıkarma, düzenleme ve silme işlemlerinin yapılabileceği, bu kriter ağırlıklarına ait verilerin bir yerde toplanarak piksel tabanlı veriye dönüştürülüp ağırlık değerlerinin girilebileceği, bütün bu piksel tabanlı veri katmanlarının üst üste bindirilerek ağırlık değerleri verilmiş haritanın elde edilebileceği, başlangıç ve bitiş noktalarının girilerek bu noktalar arasında en optimum güzergâhın bulunabileceği bir ara yüze literatürde rastlanılmamaktadır ve bu eksikliğin giderilmesi için tüm bu işlemleri içine alan bir ara yüzün geliştirilmesi gerekmektedir. Dünyada CBS ile ilgili geliştirilen birçok yazılım vardır [18]. ESRI firmasının ArcMap yazılımı CBS yazılımları içinde en yaygını olduğundan [3], bu çalışmada geliştirilen ara yüz ArcMAP programına uygun tasarlanmıştır.

ENH güzergâh çalışmalarının neticesinde belirlenen rotanın saha çalışması, uygulanması ve proje çizimi oldukça zaman alan zor bir süreçtir. Bu güzergâhlara ait projelerin çizimi günümüz şartlarında genelde, 1/25.000 ölçekli haritalarda belirlenen koridorun sahaya gidilerek güzergâh için en uygun noktaların ve hattın açı yaptığı yerlerin koordinatlarının alınması, bu koordinatlara göre hattın iki boyutlu profilinin çizim programı ortamına aktarılması, varsa atlama noktalarının, ormanlık alanların tayini ve gösterilmesi, ENH direklerinin iletken sehim şablonlarına ve menzil hesaplarına göre dikilmesi, direk tepesindeki traverslerin seçim tablolarından teker teker seçilmesi, hattın yukarı çekmeye maruz kalıp kalmadığının kontrolü, birbirine komşu menziller arasındaki oranın kontrolü vb. birçok işlemin yapılmasını gerektirmektedir. Tüm bu işlemlerin bilgisayar otomasyonuyla yapılarak kullanıcılara sunulması, ENH projelerinin daha kısa zamanda daha az hatayla yapılarak dolaylı olarak ülke ekonomisine katkı sağlaması açısından büyük önem taşımaktadır. Güzergâhı belirlenen ve çizim ortamında çizimi gerçekleştirilen ENH projelerinin üç boyutlu arazi modeli üzerinde uydu fotoğrafları yardımıyla gösterimi, hattın uygulama aşamasındaki hatalarının tespit edilmesini kolaylaştıracaktır.

Bu çalışmada, ENH güzergâh belirlemesinde yapılan işlemlerin ihtiva eden bir ara yüz geliştirilmiştir. Bu ara yüze ek olarak ENH proje çizimlerini ve diğer bütün seçim işlemlerini yapan, direk ve iletken koordinatlarını dışarı aktaran bir ENH çizim programı yazılmıştır. Örnek bir çalışma alanında ENH güzergah tespiti ve projesinin çizdirilmesi yapılmıştır. Güzergâhı belirlenen ve çizimi gerçekleştirilen ENH projesinin uydu fotoğrafı üzerinde üç boyutlu ortamda gösterimi gerçekleştirilerek yazılımların doğruluğu ve hassasiyetleri kontrol edilmiştir.

\section{ENH GÜZERGÂH TESPITİ ÇALIŞMALARI ICÇIN ARA YÜZ TASARIMI (INTERFACE DESIGN FOR ETL ROUTE DETERMINATION STUDIES)}

Bilindiği üzere CBS yazılımları çok fonksiyonları içeren oldukça karmaşık yazılımlardır. ENH güzergâh tespitinin CBS yazılımlarıyla yapılması çalışmalarında kullanıcıların çok farklı fonksiyonları kullanmaları bu işlemi zorlaştırmaktadır. Kullanıcılara, güzergâh tespitinde kullanılan tüm fonksiyonların hiyerarşik bir sırayla bir ara yüz şeklinde sunulması, kullanıcıların güzergâh tespiti çalışmalarında zamandan tasarruf sağlayarak işlemlerini kolaylaştırmaktadır. $\mathrm{Bu}$ amaçla, CBS yazılımları içinde yaygın olarak kullanılan ArcMap yazılımına, ENH güzergâhı belirleme çalışmalarında, kullanıcılar tarafindan takip edilen adımları gerçekleştirebilecek bir ara yüz tasarlanmıştır. Yaklaşık on üç bin dört yüz satır kod ihtiva eden ara yüz, C\# programlama dili yardımıyla tasarlanmıştır. Ara yüzdeki birçok işlemin ArcMap yazılımı yardımıyla gerçekleştirilmesinden dolayı ara yüz, ArcMap programına bütünleştirilmiştir.

Ara yüz ArcMap yazılımında, kullanıcının kolayca erişebilmesi için menü çubuklarına, yerleştirilmiştir. Kullanıcı, oluşturulan ara yüzü ArcMap programının herhangi bir yerine, "Customize" menüsünden "Customize mode" seçeneğini seçerek, açılan pencerede "Add from file" kutucuğu yardımıyla Visual Studio programında derlenen ".dll” dosyasını programa girerek ekleyebilmektedir. 
Ara yüzde, Şekil 1 (a)'da gösterildiği gibi kullanıcının kriterler ve ağırlıkları üzerinde ekleme, çıkarma ve düzenleme işlemlerini kolaylıkla yapabilmesi ve bu işlemleri kaydedip daha sonradan kullanabilmesi için Microsoft Access dosyasına erişebilen bir veri tabanı kullanılmıştır.

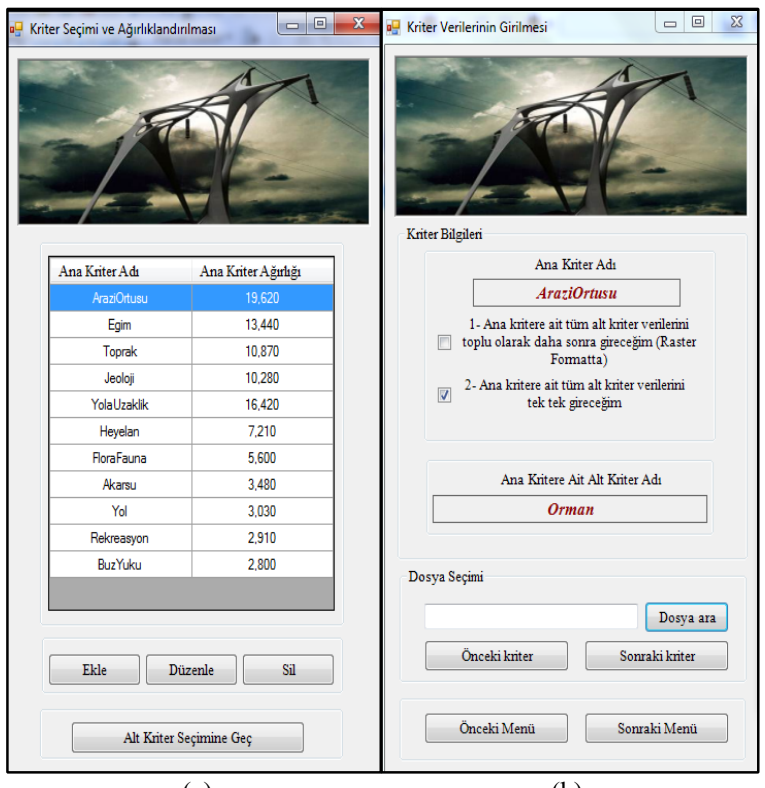

(a)

(b)

Şekil 1. (a) Ana kriterler ve ağırlık yüzdelerinin girildiği ara yüz penceresi (b) Verilerin girildiği ve hafizaya alındığı ara yüz penceresi (a) Interface window used for entering the main and sub-criteria weight percent (b) Interface window used for entering and memorizing the data

Bir sonraki menüde Şekil 1 (b), kullanıcının girilen tüm kriterlere ait verileri girilebilmesi için dosya seçim kutusu kullanılmıştır. Ayrıca kullanıcının ana kritere ait alt kriterler verilerini toplu olarak daha sonra raster (piksel tabanlı) olarak girmesine olanak sağlamak için kontrol kutucukları konulmuştur. Dosya açma menüsünde seçilen kriterlere ait dosyaların adresleri, daha sonra işlemlere tabi tutulmak üzere birer birer kaydedilmiştir. Bu menüde tüm alt kriterlere ait dosya adresleri hafizaya alınmaktadır. Kullanıcının kriterleri atlayarak işlemlerde hata yapılmasını önlemek amacıyla geçişlerde tüm adreslerin kontrolü yapılmıştır.

Şekil 2 (a)'da gösterilen menüde, bilgileri ve adresleri hafizaya alınan kriterlerin kullanıcı tarafindan belirlenen piksel boyutunda istenilen dosya yoluna kaydedilmek üzere raster formata dönüşümleri ArcMap programında ilgili komutlar ara yüzde çalıştırılarak sağlanmıştır. Bütün kriterlerin dönüşümü yapıldıktan sonra verilerin arka planda veri tabanına erişim sağlanarak ve ağırlık yüzde değerleri hesaplanarak girilmesi sağlanmıştır. Bütün bu işlemlerden sonra hafizada tutulan tüm kriterlere ait raster veriler üst üste bindirilerek seçilen kriterler ve girilen veriler doğrultusunda AMH'nin oluşturulması ara yüz ortamında yapılmıştır.

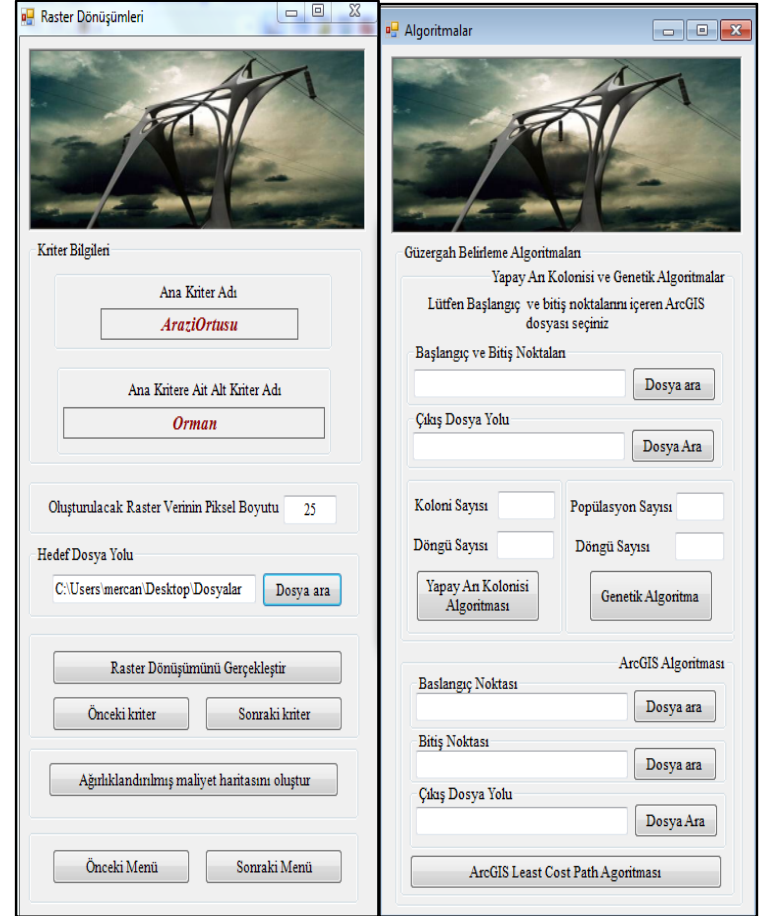

(a)

(b)

Şekil 2. (a) Dönüşümlerin yapıldığı ve ağırlık değerleri verilmiş haritanın oluşturulduğu ara yüz penceresi (b) Algoritmalar yardımıyla en uygun güzergâhın tespit edildiği ara yüz penceresi (a) Interface window used for making conversions and generating weighted maps (b) Interface window used for

Son olarak, kullanıcının güzergâha ait başlangıç ve bitiş noktalarını ara yüze girerek, bu noktalar arasında daha önce hazırlanan ve ara yüze uyarlanması sağlanan Genetik Algoritma (GA), Yapay arı kolonisi (ABC) algoritması ve ArcMap programının Cost Diatance-Cost Path (CD-CP) araç kutuları yardımıyla en uygun güzergâhın tespit edilmesi sağlanmıştır Şekil 2 (b).

\section{ENH PROJELERI ÇIZIM PROGRAMI (ETL PROJECTS DRAWING SOFTWARE)}

ENH projeleri, geçmişte sehim şablonları yardımıyla elle çizilmekteydi. Hattın profili paftaya çizildikten sonra ilk direkten itibaren iletken sehim şablonları kullanılarak bir sonraki direğin konumu belirlenmekteydi. Her iletkene göre farklı şablon kullanılmaktaydı. Günümüzde ise gelişen çizim programları kullanıcıların yükünü oldukça hafifletmiştir. Artık çizimler paftalar yerine elektronik ortamda çizim programları yardımıyla yapılmaktadır. Ancak sehim şablonları ile direk yerleşimi yine kullanıcıları uğraştıran işlemlerin başında gelmektedir. Güzergâhı belirlenmiş bir ENH'nin profilinin çizilebilmesi için hattın geçtiği sahaya gidilerek hattın açı yaptığı yerlerin, tepe noktalarının, akarsu, yol vb. atlama ve geçişlerin, direk dikilemeyecek yerlerin vb. koordinatlarının alınması gerekmektedir. 
$\mathrm{Bu}$ koordinatlara göre hattın iki boyutlu profilinin çizim programı ortamına aktarılması, varsa atlama noktalarının, ormanlık alanların tayini ve gösterilmesi kullanıcılar için zahmetli işlemlerdir. Diğer yandan direk tiplerinin ve bunlara ait traverslerin seçimi de oldukça zaman alan işlemlerdir. Direkler arazi yapısına göre, kullanıldığı yere göre (köşede taşıyıcı, durdurucu, nihayet vb.), sapma açısına göre, ağırlık menzili ve rüzgâr menziline göre direk seçim tablolarından seçilmektedir. Traversler de, maksimum menzil ve ağırlık menziline, direğin kullanımına göre (taşıyıcı, durdurucu vb.) seçilirler. Yunusoğlu (1995), "Orta Gerilim Enerji Nakil Hatları" adlı iki ciltlik kitabında, OG ENH çizimiyle ilgili tüm hesaplamaları, tabloları ve diğer tüm seçimlerin yapılışını ayrıntılı olarak ele almıştır.

Yukarıda bahsedilen aşamalar göz önünde bulundurulduğunda, ENH proje çizimleri için CBS ortamindan aktarılan hat bilgilerine göre profili çizebilen; geçişler, atlamalar, ormanlık alanlar vb. yerleri belirtebilen, girilen iletken, buz yükü bölgesi, ortalama açıklık, ekonomik direk boyu vb. bilgilere göre hesapladığı en uygun mesafelere göre direkleri yerleştirebilen; ağırlık ve rüzgâr menzillerine göre direk seçimini yapan; maksimum menzil ve ağırlık menziline göre travesleri belirleyebilen ve diğer hesapları ve seçimleri yapabilen ve çizim ortamında çizimini yapabilen bir programın yazılması ENH proje çizimlerini oldukça kolaylaştıracaktır.

$\mathrm{Bu}$ çalışma ile $\mathrm{ENH}$ projelerinin çizimlerinin elektronik ortamda yapılabilmesi için Swallow ve Raven iletkenleriyle ilgili tüm hesapları ihtiva eden bir yazılım gerçekleştirilmiştir. $\mathrm{Bu}$ yazılımda öncelikle güzergâhı belirlenen $\mathrm{ENH}$ projesinin koordinat bilgilerinin dosyaya aktarılması gerekmektedir. $\mathrm{Bu}$ işlem ArcMap ortamında, proje noktalarının gerçek hayattaki $x$, y ve $z$ koordinat bilgilerinin seçilerek "Attribute Table" menüsünden "Export" seçeneği kullanılarak "dbf" dosyasına aktarılarak gerçekleştirilmiştir.

ENH proje çizimlerinin birinci adımı, proje güzergâhı koordinat bilgilerinin çizim programına aktarılıp profilin çizilmesidir. Bu çizim işleminde hattın geçtiği güzergâh üzerinde bulunan akarsu, yol, kanal, ENH, telefon hatt, direk dikilemeyen yerler gibi gerekli tüm bilgiler, ayrıca hattın açı yaptığı dönüş noktalarındaki açı değerleri de profil üzerinde gösterilmektedir. Profil ölçeği ilk aşamada, kullanıcının AutoCAD penceresinde ölçüm işlemleri sırasında ölçek dönüşümleriyle uğraşmaması için gerçek değerlerde çizilir. Daha sonra kullanıcının projeyi onaylamasıyla istenen ölçekte çizilir.

Hazırlanan ENH çizim programı, hattın ve tüm atlamaların koordinat değerlerini içeren dosyaların kullanıcı tarafindan programa tanıttırılmasıyla, atlama yerleri ve hattın açı yaptığ 1 yerler profil çizim şablonunda yer almaktadır. Bu işlemler, Şekil 3 (a)'da gösterilen pencere üzerindeki butonlar yardımıyla yapılmaktadır. $\mathrm{Bu}$ pencerede, "Ölçek değeri" bölümünde projenin çizim ölçeği seçimi, "Atlamalar ve geçişler" bölümünde hattın atlama koordinatlarını içeren dosyaların ve atlama bilgilerinin girilmesi, "Dosya okuma" bölümünde AutoCAD programının program kontrolünde çalıştırılması ve güzergâh koordinatlarının dosyadan alınarak güzergâhın çizilmesi işlemleri yapılmaktadır.

Profil çiziminden sonra Şekil 3 (b)'de gösterilen Proje çizim penceresi açılır. Bu pencerede, ENH projesiyle ilgili olarak iletken türü, bölge, direk malzemesi, izolatör çeşidi ve türü, gerilim seviyesi vb. bilgiler programa girilir.

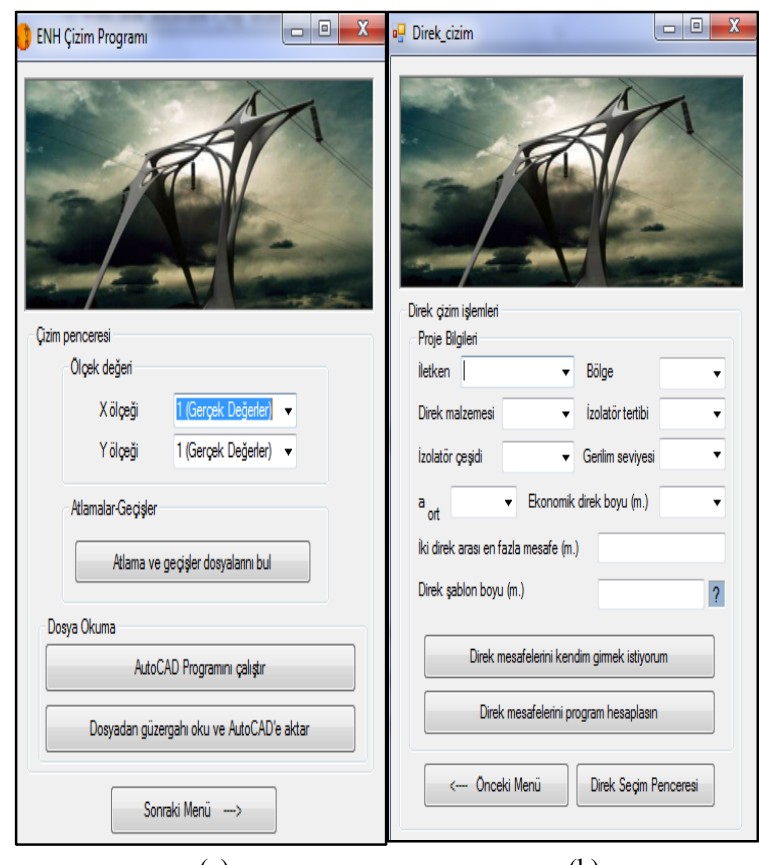

(a)

(b)

Şekil 3. (a) ENH Çizim programı giriş penceresi (b) proje çizim penceresi (a) ETL drawing software input window, (b) Project drawing window

Proje çizim penceresindeki bilgilerin girilmesinden sonra, kullanıc1, programda direk mesafelerini doğrudan girmeyi ya da programın otomatik olarak en optimum mesafelerde direkleri yerleştirmesini tercih edebilir. $\mathrm{Bu}$ işlemler, program penceresinde "Direk mesafelerini Kendim girmek istiyorum" ve "Direk mesafelerini program hesaplasın" butonları yardımıyla yapılmaktadır. Eğer direk mesafeleri kullanıcı tarafindan girilecekse Şekil 4 (a)'daki pencere açılır ve kullanıcının mevcut direkle ilgili girmek istediği değerlerin girmesi sağlanır.

$\mathrm{Bu}$ bilgiler girildikten sonra, kullanıcı penceredeki bilgileri girerek sonraki direk mesafelerini teker teker girmeye devam edebildiği gibi isterse mevcut direkten sonraki direklerin program tarafindan girilmesini de tercih edebilir. 


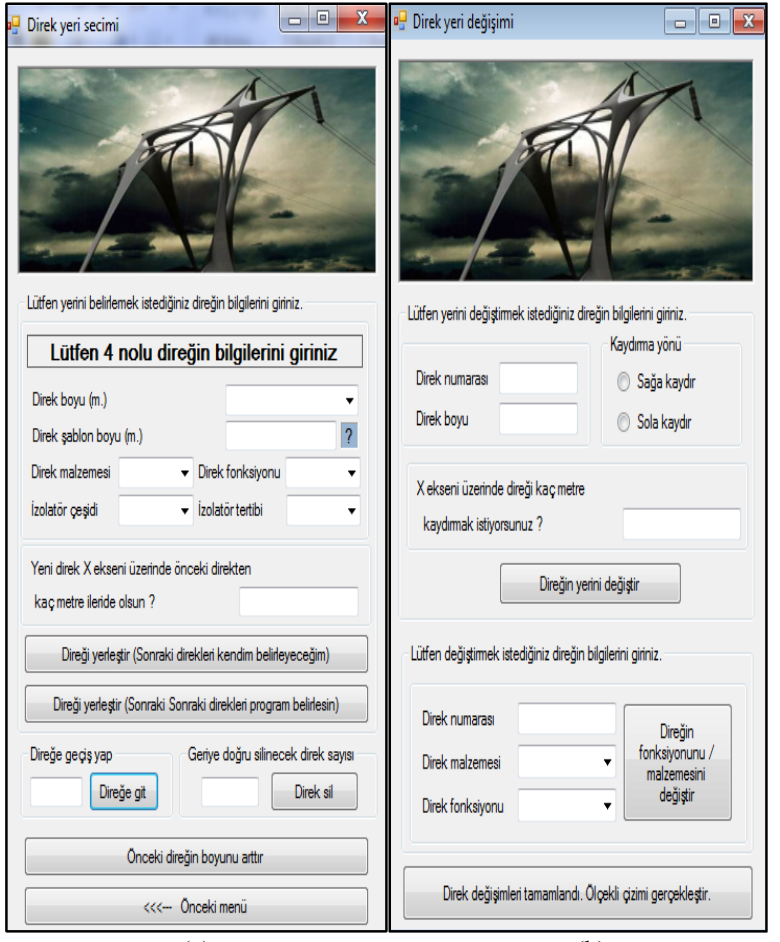

(a)

(b)

Şekil 4. (a) Kullanıcı tarafindan direklerin teker teker belirlendiği program penceresi (b) Direk değişim penceresi (a) Software window used for determination of the poles one by one by the user, (b) Pole replacing window

Direklerin program tarafindan belirlenmesinin tercih edilmesi durumunda, toplamda yaklaşık olarak otuz beş bin satırlık kod ihtiva eden program tarafindan, mevcut direkten itibaren arazinin durumuna göre en uygun mesafelerde direklerin yerleşimi; direk tipleri, travers tipleri, direk fonksiyonları vb. bütün seçimler ilgili tablolardan yapılarak direklerin yerleşimi; her bir direğin yerleşimi yapılırken bu direkle önceki direk arasında seçili iletkenin arazinin durumuna göre emniyet mesafesinde olup olmadiğ 1 ve atlama varsa, atlama mesafelerinin uygun olup olmadığının kontrolü; iletken tipine göre hattın belirli mesafelerde durdurulması gerektiğinden bu mesafenin kontrolü ve gerektiğinde hattın durdurulması; direklerin yukarı çekmeye (Up-lift) maruz kalıp kalmadığının kontrolü, birbirine komşu menziller arasındaki oranın 2,5'ten fazla olmamasının kontrolü vb. tüm kontroller yapılmaktadır. Programın herhangi bir nedenle direk veya travers seçimini yapamaması durumunda (örneğin iki direk arası olabilecek en fazla mesafeden daha uzun bir atlama olduğu durumda), ilgili direk bilgilerinin kullanıcı tarafından girilebileceği Şekil 4 (a)'daki pencere açılarak, programın bu özel durumda kullanıcının bilgisine başvurması sağlanmaktadır. Program penceresinde istenilen direğe geçiş yapılması "Direğe git" butonuyla, istenilen direğin silinmesi "Direk sil butonuyla", önceki direğin boyunun yetersiz kalması durumlarında önceki direğin boyunun arttırılması "Önceki direğin boyunu arttır" butonuyla sağlanmaktadır. Program, proje çiziminde

gerekli olan direk numarası, direk-travers adı, baştan mesafe, travers-konsol-tertip adı vb. bütün bilgilerin gerekli yerlere yazımını gerçekleştirmektedir. Ayrıca rüzgâr ve ağırlık menzilleri bilgilerinin de çizim üzerinde ilgili yerlere yazımını gerçekleştirmektedir. Son direğin de yerleştirilmesiyle kullanıcıya proje üzerindeki bilgileri onaylayıp onaylamadığı sorulmaktadır. Program tarafindan belirlenen bilgiler kullanıcı tarafindan onaylanmazsa Şekil 4 (b)'deki direk değişim penceresi açılarak direk mesafelerinin ya da direk fonksiyonlarının kullanıcı tarafindan değiştirilmesi sağlanmaktadır. Kullanıcının çizdirilen proje bilgilerini onaylamasıyla proje istenen ölçek değerinde çizilir. Program, proje ile ilgili tüm çizim işlemlerinin bitirilmesinden sonra, girilen güzergâh koordinatlarını temel alarak tayin edilen direk koordinatlarını ve hattın durumuna göre iletken koordinatlarını, daha sonradan üç boyutlu ortamda ENH projesinin gösterimi için dosyaya aktarma işlemini de kullanıcıya sormaktadır.

\section{ARA YÜZ YARDIMIYLA ÖRNEK BİR ENH GÜZERGAHININ BELIRLENMESI VE PROJESININ ÇİIILMESI (A SAMPLE ETL ROUTE DETERMINATION AND PROJECT DRAWING BY THE HELP OF THE INTERFACE)}

Oluşturulan ara yüzün performansını test etmek için, literatürde Bulanık Analitik Hiyerarşi Metoduyla (BAHM) belirlenen [2-20] kriter ve alt kriter ağırlıkları kullanılmıştır. BAHM metodunun tercih edilme nedeni klasik Analitik Hiyerarşi Metoduna göre daha sağlıklı sonuçlar vermesidir [21]. Örnek çalışma alanı olarak Gümüşhane ili seçilmiştir. Tüm kriter ve alt kriterlere ait ağırlık değerleri veri tabanına Şekil 1 (a)'daki pencere yardımıyla girildikten sonra dijital coğrafi veriler ara yüze Şekil 1 (b)'deki pencere yardımıyla aktarılmıştır. Aktarılan veriler Şekil 5 (a)'da gösterilmektedir. Gerekli raster dönüşümleri gerçekleştirildikten sonra örnek çalışma alanına ait AMH Şekil 5 (b)'de gösterildiği gibi oluşturularak bir başlangıç ve bitiş noktası arasında ENH güzergah belirlenmesi ArcMap programının CD-CP araç kutuları, Yapay arı kolonisi (ABC) algoritması ve Genetik Algoritma (GA) yardımıyla yapılmıştır. AMH haritasının oluşturulmasındaki tüm işlemler [20]'de detaylı olarak gösterilmiştir. Arıların bal kaynağı bulmada kullandıkları yöntemden ilham alan ABC algoritması basitliği ve problem çözmedeki kabiliyetinden dolayı [22] birçok optimizasyon problemine uygulandığından [20, 23-26] bu çalışmada tercih edilmiştir. GA ise "en iyi olan yaşar" olan genetik mantığını kullanan, geleneksel optimizasyon metotları içerisinde çok zor olarak kabul edilen [27], karmaşı çok boyutlu arama uzayında en iyinin bulunmasında diğer algoritmalara göre daha etkili olan [28] ve literatürde optimizasyon problemlerinin çözümünde oldukça yaygın olarak kullanılan bir algoritma olduğu için [27-31] bu çalışmada diğer algoritmalara alternatif olarak tercih edilmiştir. 


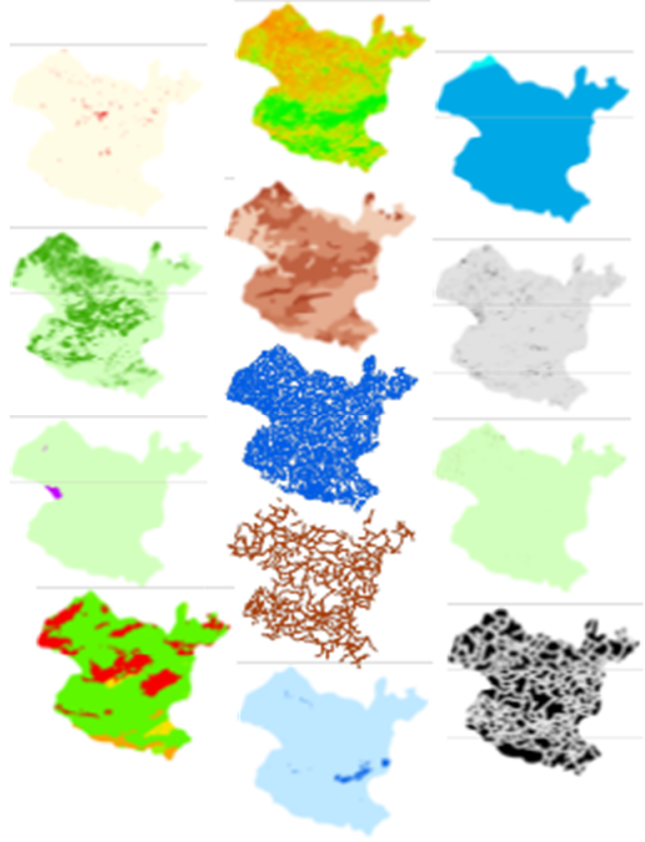

(a)

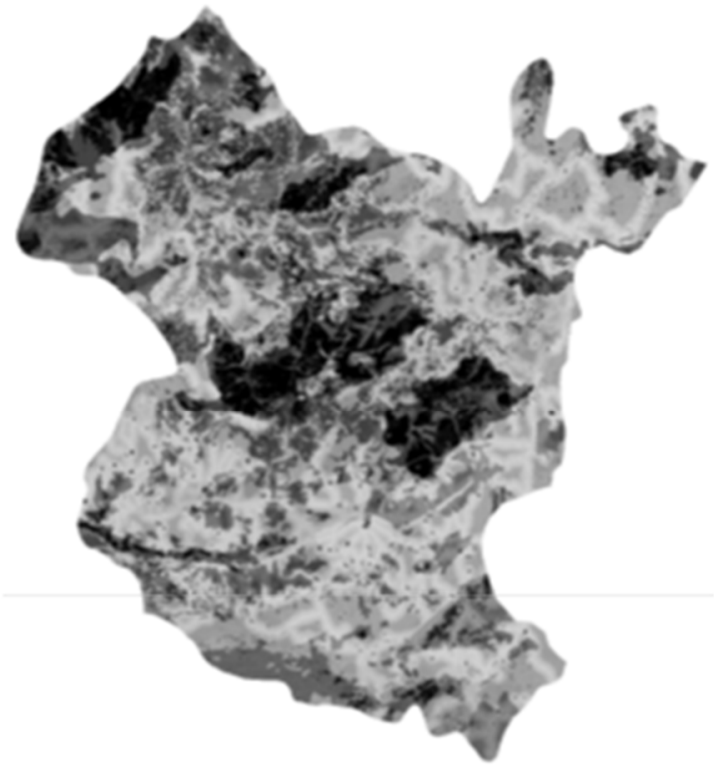

(b)

Şekil 5. (a) Tüm kriterlere ait dijital coğrafi veriler (b) Oluşturulan AMH haritası (a) The digital geographical data belonging to all criteria (b) The generated weighted surface map).

Araç kutuları yardımıyla oluşturulan alternatif güzergahlar sirasıyla Şekil 6 (a), (b) ve (c)'de gösterilmektedir. $\mathrm{Bu}$ üç çalışma alanı için bulunan rotalardan GA ve ABC algoritmalarının buldukları rotaların uygunluk değerleri ArcMap yazılımının CD$\mathrm{CP}$ araç kutusunun bulduğu uygunluk değerlerinden daha küçüktür. Fakat algoritmaların zaman performansı CD-CP araç kutusunun zaman performansı kadar iyi değildir.

Ara yüzde üç algoritmanın kullanılması kullanıcıya daha geniş bir yelpazeyle alternatifler sunacağından daha az maliyetli ENH projelerinin yapılması sağlanacaktır. Belirlenen güzergahların uygunluk değerlerinin ve algoritmaların performanslarının karşılaştırılması [20]'de ayrıntılı olarak verilmiştir.

Güzergahı belirlenen örnek bir ENH'nin 2,5 km mesafeli bir bölümünün projesi $\mathrm{ENH}$ çizim programiyla, 34,5 kV seviyesinde, Swallow iletkenli, demir direkli, düz tertip, 3. buz yükü bölgesinde çizdirilmiştir. Çizimi yapılan ENH projesi Şekil 7'de gösterilmektedir.

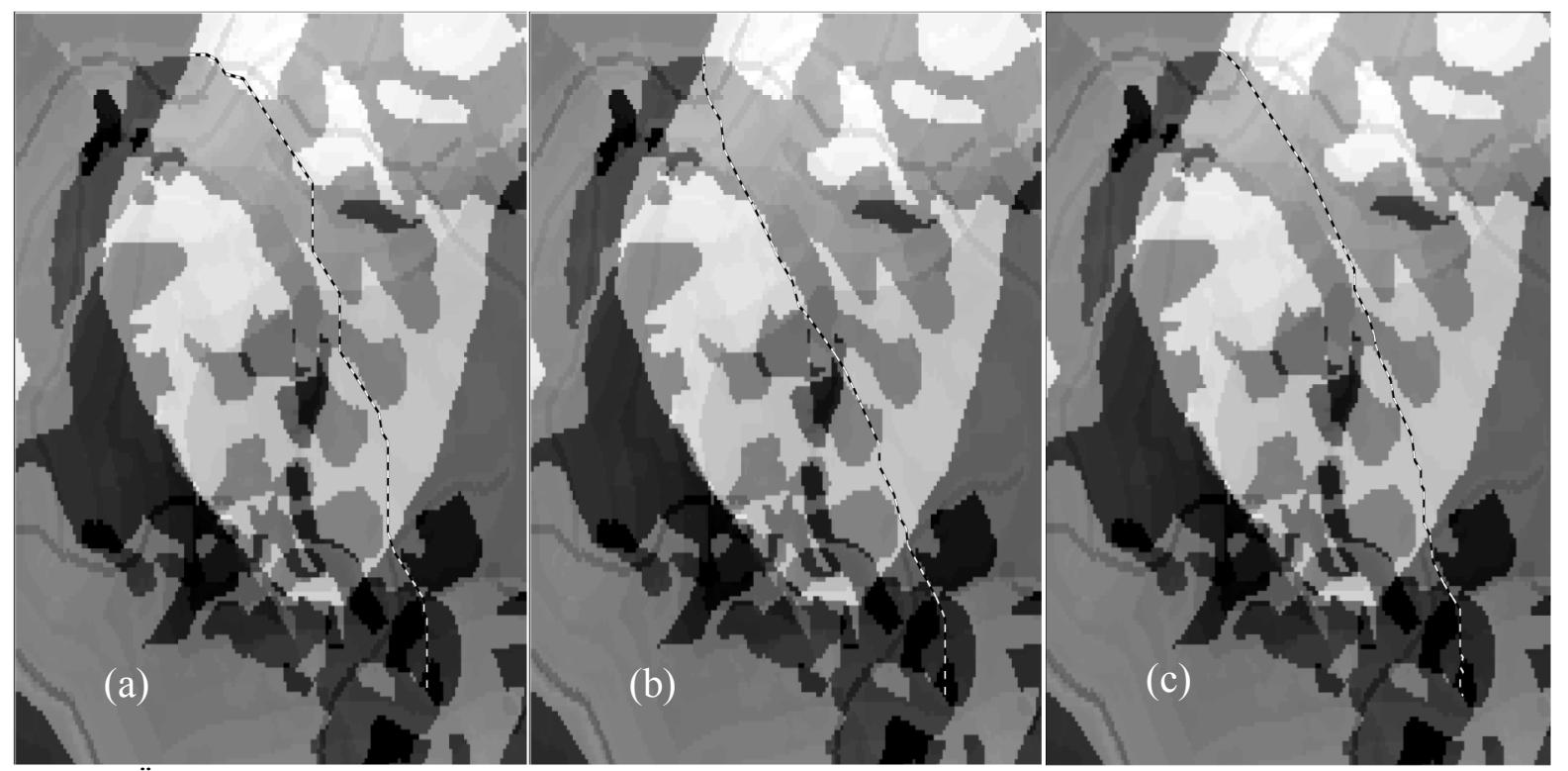

Şekil 6. Örnek çalışma alanı için elde edilen rotalar (ArcMap (a), ABC (b) ve GA (c)) (The generated routes fort he sample ) 


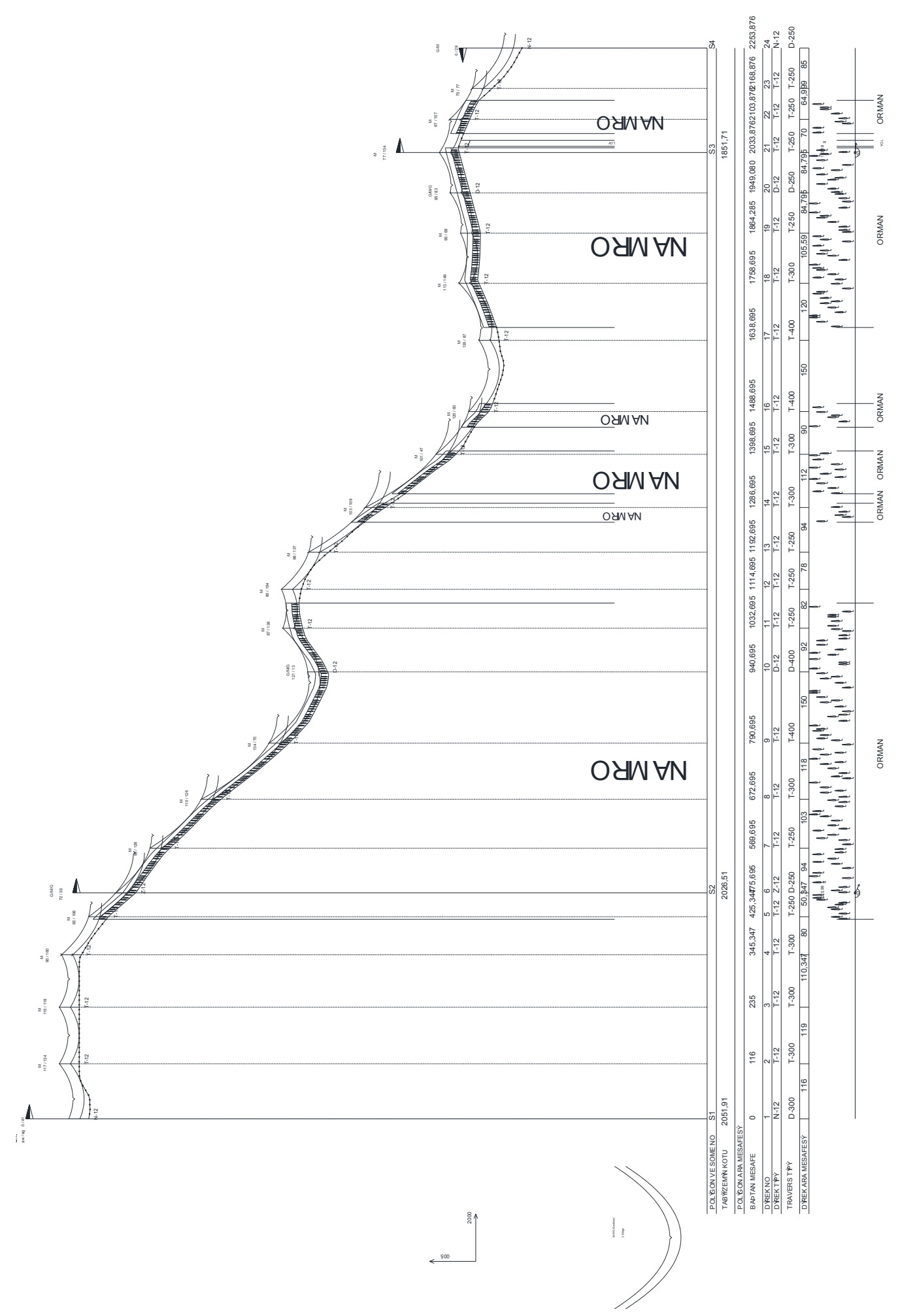

Şekil 7. Üç boyutlu gösterim için çizdirilen proje (The sample Project drawn for three-dimensional representation). 

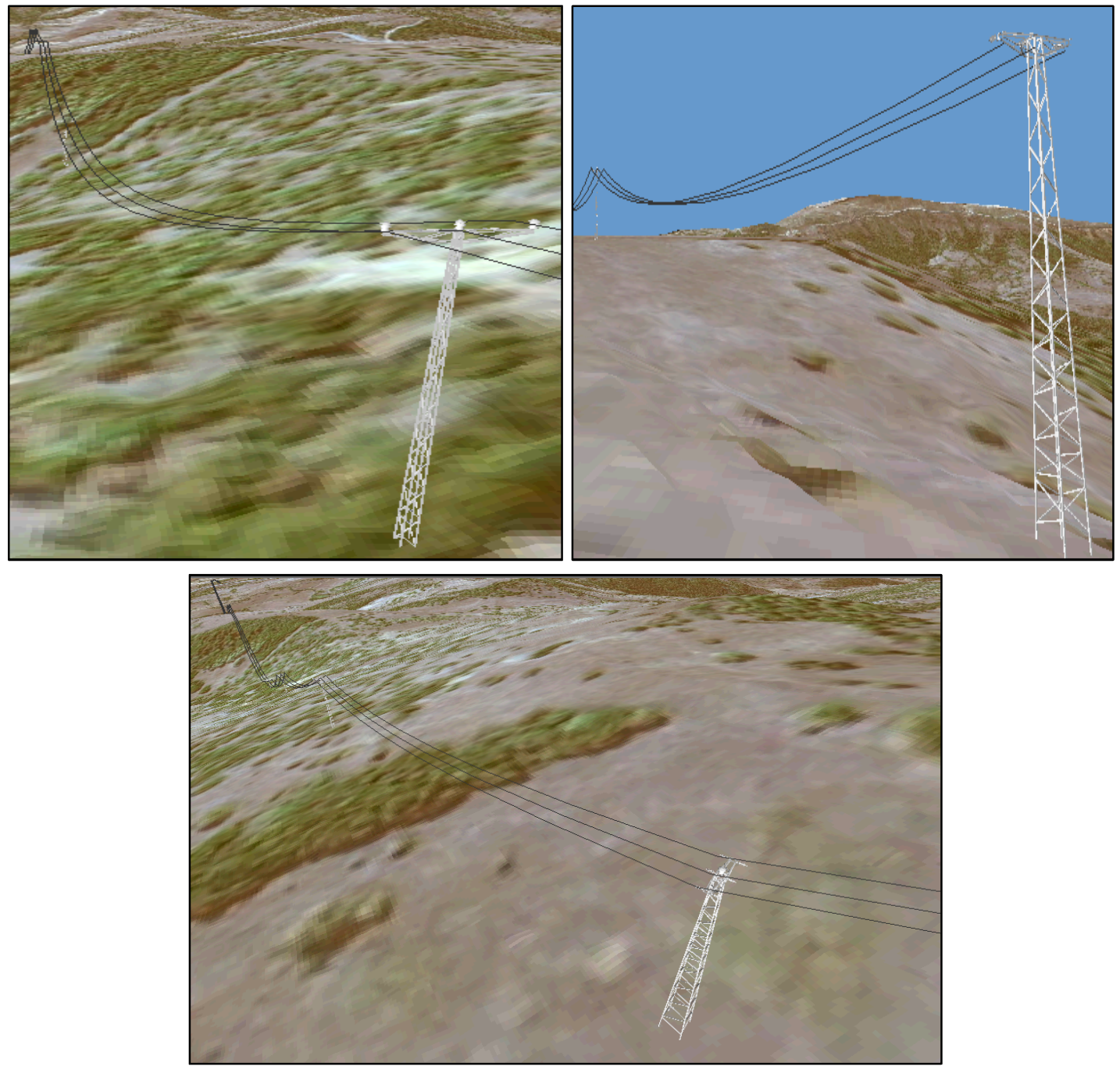

Şekil 8. Üç boyutlu ortama aktarılan örnek ENH projesinin bazı direklerinin gösterimi

(The representation of some poles transferred to three-dimensional environment in the ETL transmission line project)

\section{ENH ÇIZIM PROGRAMI TARAFINDAN ÇIZDÍRILEN PROJENIN ÜÇ BOYUTLU ARAZI ÜSTÜNDE GÖSTERIMİ (THREE-DIMENSIONAL DISPLAY OVER LAND OF THE PROJECT DRAWN BY ETL DRAWING PROGRAM)}

ENH çizim programındaki bütün proje işlemlerinin bitmesiyle, belirlenen direk koordinatlarının giriş dosya klasörü içine kaydedilmesi yapılmıştır. Burada daha önce yapılan üç boyut - iki boyut dönüşümü tersine yapılarak iki boyutta hesaplamaları yapılan proje direklerinin koordinatları üç boyutlu ortama aktarılmıștır. Daha sonra bu direkler arasına çekilen iletkenin sehim çizgisinin tüm koordinat bilgileri, belirlenen bir aralıkta alınarak, gerekli üç boyuta dönüşüm sağlandıktan sonra projeye ait tüm direk ve sehim koordinatları dosyaya aktarılmıştır.

ENH projesinin üç boyutlu arazi modeli üzerinde gösterimi için proje ile ilgili direk, travers vb. tüm parçaların üç boyutlu ortamda olması gerekmektedir. $\mathrm{Bu}$ amaçla ENH projesiyle ilgili tüm parçalar üç boyutlu ortama aktarılmıştır. $\mathrm{Bu}$ parçaların arazi modeli üzerinde ilgili noktalara yerleştirilebilmeleri için gerekli dönüşümler yapılmıştır. Proje çizimi gerçekleştirildikten ve koordinat bilgileri dosyaya kaydedildikten sonra ESRI firmasinın ArcMap yazılımına ek olarak geliştirdiği ve üç boyutlu coğrafi işlemlerin yapıldığı ArcGlobe ile üç boyutlu arazi modelinin üzerine çalışma alanını içine alan ve yaklaşı boyutu 300 GB olan uydu fotoğrafi bindirilmiștir. Direk ve hattın tertibine, iletkenin tipine, hattın dönüş açısına vb. değişkenlere göre hesaplanan sehim koordinatları üç boyutlu haritaya aktarılmıştır. ArcGlobe ortamında noktasal veri ile gösterilen koordinatlar ArcGlobe'un "Point to line" dönüştürücü araç kutusu yardımıyla çizgisel veriye dönüştürülür ve ENH çizim programıla hesaplamaları yapılan iletken sehimlendirmesi üç boyutlu ortamda gösterildiği gibi elde edilmiştir. Noktasal olarak ArcGlobe ortamina aktarılan direk koordinatlarına, ENH çizim programıla belirlenen direk ve travers bilgilerine göre üç boyutlu direk ve traversler uygun direk boylarında yerleştirilmiştir ve hattın doğrultusuna göre hesaplanan dönüş açılarına göre direkler bu yönde döndürülmüștür. Şekil 8 'de üç boyutlu ortama aktarılan örnek ENH projesinin bazı direkleri gösterilmektedir. 


\section{SONUÇLAR (CONCLUSIONS)}

Bu çalışmada, ENH'ler için en uygun güzergâhın belirlenmesinde, literatürde eksikliği görülen ve kullanıcıların güzergah tespiti işlemlerini kolaylaştıran, kriter ve alt kriter bilgilerinin düzenlenebileceği, veri ve dönüşüm işlemlerinin yapılabileceği, algoritmalar ve CD-CP araç kutusu ile güzergah bulma işlemlerinin yapılabileceği bir ara yüz tasarlanarak ArcMap programına bir araç kutusu olarak eklenmiştir. Güzergâhı belirlenen ENH hattının Swallow ve Raven iletkenleri için proje çizimlerinin tüm aşamalarını ve hesaplamalarını yapabilen ve tüm çizim işlemlerini yerine getirebilen ve sonuçta elde edilen direk ve sehim koordinat bilgilerini hesaplayarak dosyaya aktarabilen bir ENH çizim programı yazılmıştır. Oluşturulan ara yüzün örnek çalışma alanında güzergâh belirleme ve proje çizdirme uygulamaları yapılmıştır. Üç boyutlu arazi modelinin üzerine uydu fotoğrafinın bindirilmesiyle elde edilen üç boyutlu harita üzerine, ENH çizim programının örnek bir proje için belirlediği direk ve sehim koordinatlarının yerleştirilmesi, gerekli dönüşümlerin sağlanması ve ENH projelerinde kullanılan parçaların üç boyutlu modellerinin eklenmesiyle çizimi yapılan projenin gerçek hayatta arazi üzerindeki gerçek modellemesi yapılmıştır.

Bu çalışmada geliştirilen yazılımlar, ENH'ler için en uygun güzergâhın tespiti ve proje çizimi çalışmalarındaki tüm işlem adımlarını, kullanıcı için oldukça kolaylaştırmasının yanında projelerin üç boyutlu gerçek arazi modeli üzerinde kontrolünü sağlayacaktır. ENH'nin güzergahının belirlenmesi, projesinin çizilmesi ve üç boyutlu ortamda gerçek koordinat ve boyut değerleriyle gösteriminin yapılarak gerekli kontrollerin araziye çıkılmadan yapılabilmesi gibi tüm işlemlerin bir çatı altına alınarak bu çalışmada gerçekleştirilmesi, bu ara yüzün önemini ve özgünlügünü arttırmaktadır.

\section{KAYNAKLAR (REFERENCES)}

1. Kahraman, C. ve Kaya, I., "A fuzzy multicriteria methodology for selection among energy alternatives", Expert Systems withApplications, Cilt 37, 6270-6281, 2010.

2. Eroğlu, H. ve Aydin, M., "Optimization of Electrical Power Transmission Lines' Routing using AHP, Fuzzy AHP and GIS", Turk. J. Elec. Eng. \& Comp. Sci., DOI: 10.3906/elk-1211-59, 2013.

3. Yıldırım, V., Doğalgaz iletim hatlarının belirlenmesi için coğrafi bilgi sistemleri ile raster tabanlı dinamik bir modelin geliştirilmesi, Doktora Tezi, Karadeniz Teknik Üniversitesi Fen Bilimleri Enstitüsü, 2009.

4. Yomralıŏlu, T., "Coğrafi Bilgi Sistemi Nedir", Coğrafi Bilgi Sistemleri: Temel Kavramlar ve Uygulamaları, Akademi Kitabevi, 2005.
5. Durduran, S. S. ve Aydin, M., "Coğrafi Bilgi Sistemleri Kullanılarak elektrik enerji nakil Hatlarının Güzergah Seçimi ve Örnek Bir Uygulama", 3. Ulusal Mühendislik Ölçmeleri Sempozyumu, Konya, 459-464, 24-26 Ekim 2007.

6. Feldman, S. C. ve Ark., "A Prototype for Pipeline Routing Using Remotely Sensed Data and Geographic Information system Analysis", Remote Sens. Environ., Cilt 53, 123-131, 1993.

7. Warner, L., L. ve Diab, R., D., "Use of geographic information systems in an environmental impact assessment of an overhead power line", Impact Assessment and Project Appraisal, Cilt 20, № 1, 39-47, 2002.

8. Nataraj, S., "Analytic hierarchy process as a decision-support", Issues in Information Systems, Cilt 6, 16-21, 2005.

9. Nonis, C., N. Ve Ark., "Investigation of an AHP based multi criteria weighting scheme for GIS routing of cross country pipeline projects", 24th International Symposium on Automation\& Robotics in Construction, Madras (India), 397-403, 19-21 Eylül 2007.

10. Schmidt, J., A., Implementing a GIS Methodology for Siting High Voltage Electric Transmission Lines, Saint Mary's University of Minnesota University Central Services Press, Minnesota, 1999.

11. Yildirim, V. ve Nisanci, R., "Developing a geospatial model for power transmission line routing in Turkey", FIG Congress 2010, Sydney, 11-16 Nisan 2010.

12. Wan, J., ve Ark., "The application of AHP in oil and gas pipeline route selection", 19th International Conference on Geoinformatics, Shanghai, Cilt 10, 1-4, 24-26 Haziran 2011.

13. Balogun, A. ve Ark., "Optimal Oil Pipeline Route Selection using GIS: Community Participation in Weight derivation and Disaster Mitigation", International Conference on Future Environment and Energy (IPCBEE), Singapoore, Cilt 28, 100-104, 2012.

14. Mali, V. ve Ark., "Enhanced routing in disaster management based on GIS", International Conference on Intuitive Systems \& Solutions, Mumbai, 14-18, 5-6 Ocak 2012.

15. Selçuk, L., "An avalanche hazard model for bitlis province, Turkey,using gis based multicriteria decision analysis", Turk. J. of Earth Sci., Cilt 22, 523-535, 2013.

16. Zsigraiová, Z. ve Ark., "Operation costs and pollutant emissions reduction by definition of new collection scheduling and optimization of MSW collection routes using GIS. The case study of Barreiro, Portugal", Waste management, Cilt 33, No 4, 793-806, 2013.

17. Tüdeş, Ş., "Proposal of the analytical model on the evaluation of the geological thresholds in planning: case study portsmounth (england)", 
Journal of the Faculty of Engineering and Architecture of Gazi University, Cilt 26, No 2, 273-288, 2011.

18. Gürer İ, Uçar İ., "Simulation of the runoff hydrograph by SRM supported by gis and remote sensing (Kayseri-Sariz creek watershed case study)". Journal of the Faculty of Engineering and Architecture of Gazi University, Cilt 28, No 1, 91-101, 2013.

19. Demircan, S., "Çoklu Etmenler Kullanılarak Enerji Nakil Hattı Güzergâh Optimizasyonu”, Yüksek Lisans Tezi, Selçuk Üniversitesi, Fen Bilimleri Enstitüsü, 2009.

20. Eroğlu, H., “Coğrafi Bilgi Sistemleri Kullanılarak Gerçekleștirilecek Olan Bilgisayar Destekli Bir Modelle Elektrik Enerii Nakil Hatlarının Güzergâh Optimizasyonu”, Doktora Tezi, Selçuk Üniversitesi, Fen Bilimleri Enstitüsü, 2014.

21. Kul, Y., Şeker, A., Yurdakul, M. "Usage of fuzzy multi criteria decision making methods in selection of nontraditional manufacturing methods". Journal of the Faculty of Engineering and Architecture of Gazi University, Cilt 29, No 3, 589-603, 2014.

22. Dongli, Z., Xinping, G., Yinggan, T., Yong, T., 2012, "An Artificial Bee Colony Optimization Algorithm Based on Multi-exchange Neighborhood", 2012 Fourth International Conference on Computational and Information Sciences, 211-214. doi:10.1109/ICCIS.2012.63.

23. Eke İ., Taplamacioğlu M., Kocaarslan İ., "Design of robust power system stabilizer based on artificial bee colony algorithm". Journal of the Faculty of Engineering and Architecture of Gazi University, Cilt 26, No 3, 683-690, 2011.

24. Öztürk., C., "Artificial bee colony algorithm for dynamic deployment of wireless sensor networks", Turkish J Electr Eng Comput Sci, Cilt 20, 255-262, 2012.

25. [25] Öztürk C., Hancer E., Karaboga D., "Automatic clustering with global best artificial bee colony algorithm", Journal of the Faculty of Engineering and Architecture of Gazi University, Cilt 29, No 4, 677-687, 2014.

26. Sönmez., Y., "Estimation of fuel cost curve parameters for thermal power plants using the ABC algorithm", Turkish J Electr Eng Comput Sci, Cilt 21, 1827-1841, 2013.

27. Öztürk A., Duman S., "Determination of the conditions of optimal operation in power systems using genetic algorithm", Journal of the Faculty of Engineering and Architecture of Gazi University, Cilt 24, No 3, 539-548, 2009.

28. Kalinli A., Aksu Ö., "Genetic algorithm model based on dominant gene selection operator", Journal of the Faculty of Engineering and Architecture of Gazi University, Cilt 26, No 4, 869-875, 2011.

29. Demirel N., Gökçen H., Akçayol MA., Demirel E., "A hybrid genetic algorithm for multistage integrated logistics network optimisation problem". Journal of the Faculty of Engineering and Architecture of Gazi University, Cilt 26, No 4, 929-936, 2011.

30. [30] Dener M., Akcayol MA., Toklu S., Bay FÖ., "Genetic algorithm based a new algorithm for time dynamic shortest path problem". Journal of the Faculty of Engineering and Architecture of Gazi University, Cilt 26, No 4, 915-928, 2011.

31. [31] Aydemir M., "Performance of some optimization methods for patch antenna problems", Journal of the Faculty of Engineering and Architecture of Gazi University, Cilt 29, No 3, 579-588, 2014. 